\title{
EFFECTS OF OZONE AND DENSITY INTERACTION ON THE GROWTH, DEVELOPMENT AND YIELD FORMATION OF RICE
}

\author{
PENG, B.* - FENG, G. N. - Zhen, Q. - QIU, M. \\ Jiangsu Key Laboratory of Biochemistry and Biotechnology of Marine Wetland, Yancheng \\ Institute of Technology, 1 Hope Avenue, 224053 Yancheng, Jiangsu, China \\ *Corresponding author \\ e-mail:ycitpbin@163.com \\ (Received $27^{\text {th }}$ Apr 2018; accepted 20 $0^{\text {th }}$ Jun 2018)
}

\begin{abstract}
To further study the effect of ozone stress on growth and yield formation of rice (Oryza sativa), we conducted an experiment with rice by using Free Air gas Concentration Enrichment (FACE) facility stored in paddy field in China. A conventional indica cultivar Yangdao 6 and a super hybrid indica cultivar II you 084 were grown at current or elevated ozone concentration (target at 50\% above current, E- $\mathrm{O}_{3}$ ) under low (LD, 16 hills $\mathrm{m}^{-2}$ ), medium (MD, 24 hills $\mathrm{m}^{-2}$ ) or high planting density (HD, 32 hills $\mathrm{m}^{-2}$ ) from tillering until maturity. The increase of $\mathrm{O}_{3}$ had no significant effect on phenology and plant height of Yangdao 6, but greatly accelerated phenology development and reduced plant height of II you 084. Ozone stress significantly reduced dry matter production of rice in mid and late stage, and finally, decreased the biomass of Yangdao 6 and II you 084 by $17.6 \%$ and $25.4 \%$ respectively. Ozone stress had no significant effect on harvest index of Yangdao 6 but reduced it of II you 084 by $9.0 \%$. The increase of $\mathrm{O}_{3}$ had no significant effect on the panicle number per area of rice. Ozone stress had no significant effect on the spikelet number per panicle of Yangdao 6, but significantly reduced that of II you 084 by $22.0 \%$. Ozone stress decreased spikelets per area, filled grain percentage, and filled grain weight of rice, and eventually reduced grain yield of Yangdao 6 and II you 084 by 15.9\% and 27.3\% respectively. Variance analysis showed that the impacts of ozone stress on II you 084 were bigger than Yangdao 6, which were proved by the significant ozone by cultivar interactions for biomass, harvest index, spikelet number per panicle, spikelet number per area, filled grain percentage, filled grain weight. Week interactions of ozone by cultivar by planting density were detected: The effects of ozone stress on biomass and grain yield of Yangdao 6 were decreased with the increase of planting density. The above results showed that the increase of $\mathrm{O}_{3}$ depressed the dry matter production of rice, and then decreased the yield, and the response of super hybrid rice varieties to ozone is greater than that of conventional varieties. The selection of highyielding conventional varieties combined with relatively high planting density can minimize the yield loss in the future high ozone conditions.
\end{abstract}

Keywords: rice, ozone, plant density, yield formation

\section{Introduction}

In recent decades, due to the aggravation of human activities, the use of a large number of fossil fuels and nitrogenous fertilizers and the emission of automobile tail gas, the concentrations of NOx and VOCs in the atmosphere have increased dramatically, resulting in the increasing concentration of ozone in the atmosphere near the ground. According to observations, the concentration of $\mathrm{O}_{3}$ in the troposphere of the Northern Hemisphere is increasing at an annual rate of $1 \%$ (WMO, 1991), even more in some industrial areas (Logan, 1985). It is reported that the average ozone concentration in the troposphere of the earth has risen rapidly from less than $10 \mathrm{nl} / \mathrm{L}$ before the industrial revolution (Volz and Kley, 1988) to about $50 \mathrm{ml} / \mathrm{L}$ in 2000 (Fiscus et al., 2005). According to Fuhrer et al.'s (1997) study, the ozone concentration has exceeded $25 \%$ of sensitive crops' injury concentration $(40 \mathrm{nl} / \mathrm{L})$. It is estimated that nearly a quarter of the countries and regions in the world now face the threat of $\mathrm{O}_{3}$ concentration 
of more than $60 \mathrm{nl} / \mathrm{L}$ in summer (Fowler et al., 1999). It is estimated that by 2050, the concentration of $\mathrm{O}_{3}$ in the troposphere will increase by $20 \%$ to $25 \%$ (IPCC, 2007), and by 2100 by $40 \%$ to $60 \%$ (Morgan et al., 2006; Sitch et al., 2007; Meehl et al., 2007). The pessimistic estimate is that the concentration of $\mathrm{O}_{3}$ in the troposphere will rise to $80 \mathrm{nl} / \mathrm{L}$ by 2100 (Fiscus et al., 2005).

The response of rice growth and yield formation under ozone stress has been widely reported (Yang et al., 2008; Ainsworth, 2008). The results showed that the response of yield to ozone stress varies greatly due to the control equipment of the experiment (Maggs et al., 1995), materials (Kobayashi et al., 1995; Maggs and Ashmore, 1998; Zheng et al., 1998; Jin et al., 2000; Li et al., 2017), the concentration of $\mathrm{O}_{3}$ treatment materials (Bai et al., 2002; Jin et al., 2001; Feng et al., 2003) and the treatment period (Asakaw et al., 1981; Heagle et al., 1991). But does the response of rice growth and yield formation to the increase of ozone concentration vary with other environment or cultivation factors? Due to the limitation of the air chamber's narrow test space, there are few reports in this aspect. Because of the large experimental space and long duration, FACE platform provides an opportunity to study the interaction between ozone and other factors (Long and Ainsworth, 2005; Lie et al., 2014; Peng et al., 2016). In recent years, the influence of ozone and other factors, especially $\mathrm{N}$, on rice (Luo et al., 2012, 2013) or wheat (Chen et al., 2011a, b) has been studied by FACE platform. As a common cultivation measure, could planting density regulate rice growth and yield formation under high ozone concentration? And does this regulation vary from variety to variety? There have been no previous reports, which is more realistic for the future development of strategies for rice production under higher surface ozone concentrations. According to the experimental materials, most of the previous studies focused on conventional rice varieties, but less on hybrid rice and even less on super hybrid rice. As has been reported in the past, the yield response of rice varieties and hybrid rice varieties to ozone stress was more significant (Shi et al., 2009; Wang et al., 2012; Luo et al., 2013). But what is the difference between the growth and yield response of super rice under ozone stress and other types of varieties? Is the yield loss similar or even greater to hybrid rice? In order to solve these problems, the effect of ozone stress on growth, development and yield formation under different densities were analyzed by using China $\mathrm{O}_{3}$-FACE platform and conventional indica rice of Yangdao 6 and Super hybrid rice of II you 084 in order to provide some guidance for rice production strategies and high-yield cultivation measures under the condition of high ozone concentration in the future.

\section{Materials and methods}

\section{Ozone-FACE platform}

The experiment was conducted on the China $\mathrm{O}_{3}$-FACE platform, which was located at Xiaoji town, Jiangdu County, Jiangsu province, China $\left(119^{\circ} 45^{\prime} \mathrm{E}, 32^{\circ} 35^{\prime} \mathrm{N}\right)$. The site, at $5 \mathrm{~m}$ above the sea level in elevation, sits in the subtropical marine climatic zone. Throughout the period of 113 days from June 21 to October 17 for the experiment in 2012, mean daily temperature was $24.5^{\circ} \mathrm{C}$, mean daily integral solar radiation (or PAR) was $13.9 \mathrm{MJ} \mathrm{m}^{-2}$, and mean daytime (6:00-18:00) vapor pressure deficit was $0.67 \mathrm{kPa}$ (Tang et al., 2011). This site has been in continuous cultivation for more than 1000 years with rice-wheat or rice-rapeseed rotation. Detailed descriptions of the soil properties for the site can be found in our previous publication (Shi et al., 2009). 
Details of the design and performance of this $\mathrm{O}_{3}$-FACE system are provided by Tang et al. (2011). In brief, The FACE system has eight $240 \mathrm{~m}^{2}$ plots, of which four replicate plots were exposed to elevated ozone concentration (hereinafter called $\mathrm{E}_{-} \mathrm{O}_{3}$ plots) and four equal size plots were in current ozone concentration (current ambient ozone concentration, $\mathrm{C}-\mathrm{O}_{3}$ plots). Any one of the $\mathrm{E}-\mathrm{O}_{3}$ plots was separated from other plots by at least $70 \mathrm{~m}$ to avoid cross contamination. The quantity and direction of the ozone release for each $\mathrm{E}_{-} \mathrm{O}_{3}$ plot was controlled by a proportional integral derivative algorithm for computer feedback that compares achieved ozone concentration to the target ozone concentration of 1.5 times current ozone concentration (simulating the predicted ozone concentration at the end of the century) with an ozone monitor (model 49i, Thermo Environmental Instruments, MA, USA), a data logger-controller, an anemometer and a wind vane. Current ozone concentration at canopy height was monitored with separate $\mathrm{O}_{3}$ analyzers in two of the $\mathrm{C}-\mathrm{O}_{3}$ plots at a 2-min interval. Every $10 \mathrm{~min}$, a control computer accessed all the data logger-controllers in $\mathrm{C}-\mathrm{O}_{3}$ and $\mathrm{E}-\mathrm{O}_{3}$ plots to collect the latest ozone concentration. A mixed gas consisting of about $5 \%$ ozone and $95 \% \mathrm{O}_{2}$ was produced by an ozone generator (KCF-BT0.2, Jiangsu Koner Ozone Co., Ltd, Yangzhou, China). The mixed gas was released in a stream of compressed air into the plots through the ABS pipes positioned at about $50 \mathrm{~cm}$ above the canopy. In the ambient plots, plants were grown under ambient ozone conditions without the ring structures. The ozone fumigation began on 1st July and continued throughout the rice season until harvest, from 9:00 am to 16:00 pm every day, only suspended in these conditions, such as ozone concentration in the control cycle lower than $20 \mathrm{~nL} / \mathrm{L}$, leafs moistened by rain and dew, ozone analysis device correction, and equipment overhaul, so the actual mean ozone concentration in FACE cycle during the entire growing season of rice was higher approximately $27 \%$ than that in the control cycle. Figure 1 shows the seasonal change in daily 7-h mean ozone concentration for $\mathrm{C}-\mathrm{O}_{3}$ and $\mathrm{E}-\mathrm{O}_{3}$ plots.

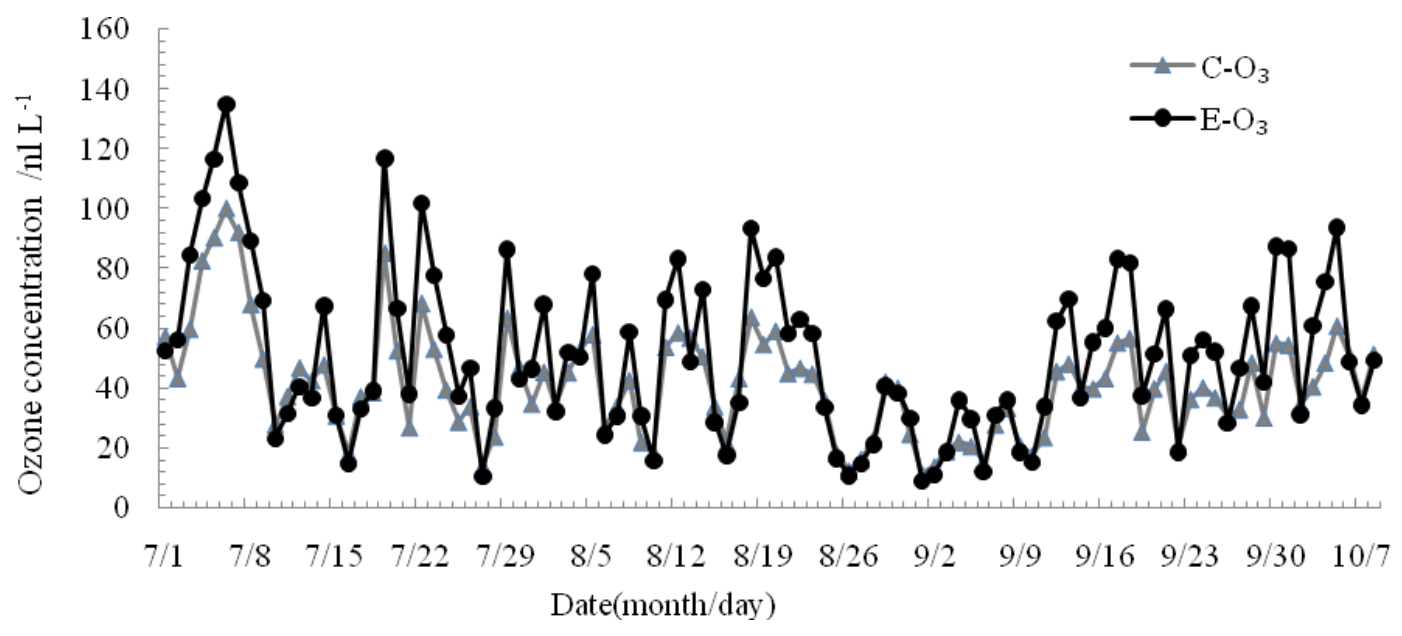

Figure 1. The change of day time 7-h average ozone concentration during ozone fumigation. $C$ $\mathrm{O}_{3}$ : Current $\mathrm{O}_{3}$ concentration; $\mathrm{E}_{-} \mathrm{O}_{3}$ : Elevated $\mathrm{O}_{3}$ concentration; The same below

\section{Plant material and cultivation}

The rice varieties are conventional indica Yangdao 6 (the variety features can not be separated from their offspring) and super hybrid indica II you 084 (the variety that was 
produced by cross breeding, and had heterosis in yield). Rice seeds were sown on 21 May; the seedlings were grown under current air and were manually transplanted into the $\mathrm{C}-\mathrm{O}_{3}$ and $\mathrm{E}-\mathrm{O}_{3}$ plots with one seedling per hill on 21 June 2012. Nitrogen (N) was supplied as urea $(\mathrm{N}=46 \%)$ and compound chemical fertilizer $\left(\mathrm{N}: \mathrm{P}_{2} \mathrm{O}_{5}: \mathrm{K}_{2} \mathrm{O}=15: 15: 15\right)$ at a rate of $15 \mathrm{~g} \mathrm{~N} / \mathrm{m}^{2}$. Of the total $\mathrm{N}, 50 \%$ was applied as the basal dressing on 20 June, $10 \%$ was top-dressed on 7 July and $40 \%$ top-dressed on 7 August. Both phosphorus (P) and potassium $(\mathrm{K})$ were applied as compound chemical fertilizer at equal rates of $7 \mathrm{~g} / \mathrm{m}^{2}$ as the basal dressing at $1 \mathrm{~d}$ before transplanting. Standard cultivation practices as commonly performed in the area were followed in all experimental plots. In brief, the paddy fields were submerged with water of about $3 \mathrm{~cm}$ in depth from 21 June to 4 July, and then the fields were subjected to wet-dry cycles through natural drainage and intermittent irrigation. At $10 \mathrm{~d}$ before harvest, irrigation was terminated to allow paddy fields to dry for final harvesting. Pesticides and fungicides were applied when necessary throughout the experiment.

\section{Experimental treatment}

This trial was a split plot experiment, in which ozone concentration was the main plot, and the treatment of varieties and transplanting density was the split plot, repeated each treatment four times, so there were 12 treatments and 48 plots in total. The transplanting density was determined as three densities including low density $\left(16\right.$ hills $/ \mathrm{m}^{2}$, planting spacing $\left.25 \mathrm{~cm}\right)$, medium density $\left(24\right.$ hills $/ \mathrm{m}^{2}$, planting spacing $16.7 \mathrm{~cm} \times 5 \mathrm{~cm})$, and high density $\left(32\right.$ hills $/ \mathrm{m}^{2}$, planting spacing $\left.12.5 \mathrm{~cm} \times 25 \mathrm{~cm}\right)$.

\section{Plant phenology, plant height and tillering dynamics}

The date for heading (50\% of plant headed) and grain maturity was recorded in each subplot. Plant height and tiller numbers were measured for fixed 10 hills in each treatment at 5-10 days intervals until heading. The productive tiller ratio (\%) was expressed as the panicle number per square meter/ the maximum tiller number per square meter $\times 100$.

\section{Dry matter production}

Eight plants (hills) were randomly selected at tillering, jointing, heading and maturity stage. The samples were separated into green and senescent leaf, stem (including leaf sheath), and panicle (when applicable). Each plant organ was dried in an oven at $105{ }^{\circ} \mathrm{C}$ for $30 \mathrm{~min}$, then at $80{ }^{\circ} \mathrm{C}$ until dry weight was constant. The dry matter accumulation and distribution among different organs during each growth period were calculated. The dry weight per stem at heading stage $(\%)$ was expressed as the dry weight per plant at heading stage / the stem number per plant. The ratio of spikelet number to stem dry weight (number/g $\mathrm{g}^{1}$ ) was expressed as the spikelet number per panicle/the dry weight per plant at heading stage.

\section{Grain yield and yield components}

Actual grain yield was determined of all the plants (60 hills) from a 4, 3, and $2 \mathrm{~m}^{2}$ patch in each LD (low density), MD (medium density) and HD (high density) subplot, respectively. The grains were air dried and weighted to obtain actual grain yield. Grain yield components, i.e. the number of panicles per square meter, the number of spikelets 
per panicle, filled grain percentage, and individual grain mass, were determined at crop maturity with six hills of plants in each subplot. Grains were soaked in tap water (specific gravity $=1.0$ ) and the number of sunken and floated grains was counted to determine the filled grain percentage. The sunken (filled) grains were oven-dried at $80^{\circ} \mathrm{C}$ until constant weight achieved. low, medium and high density.

\section{Statistical analysis}

A split-plot design was employed with $\left[\mathrm{O}_{3}\right]$ as main-plot treatment, varieties and planting density as the split-plot treatment. Analysis of variance (ANOVA) was performed using the software Statistical Product and Service Solutions (SPSS Inc., Chicago, IL, USA) to determine the main effects of $\left[\mathrm{O}_{3}\right]$, variety, planting density and the effects of their interaction. Treatments were compared by Tukey's test and differences were declared statistically significant if $p<0.05$.

\section{Results}

\section{Plant phenology and plant height}

$\mathrm{O}_{3}$ treatment had no significant effects on phenology development and plant height of Yangdao 6. However, high concentration of $\mathrm{O}_{3}$ advanced the heading stage of II you 084 by 3 days and the mature stage by 7 days (Table 1; Fig. 2). High concentration $\mathrm{O}_{3}$ decreased the plant height of Yangdao 6, but did not reach the significant level, and decreased the height of II you 084 by $0.5 \%, 1.3 \%$ and $6.7 \%(p<0.05)$ and $7.8 \%$ ( $p<0.05)$ after transplanting at 23, 45, 66 and $113 \mathrm{~d}$ (Fig. 3). The results of variance analysis showed that the interaction between $\mathrm{O}_{3}$ and varieties had a weak interaction effects on plant heights at the mature stage of rice $(p=0.16)$.

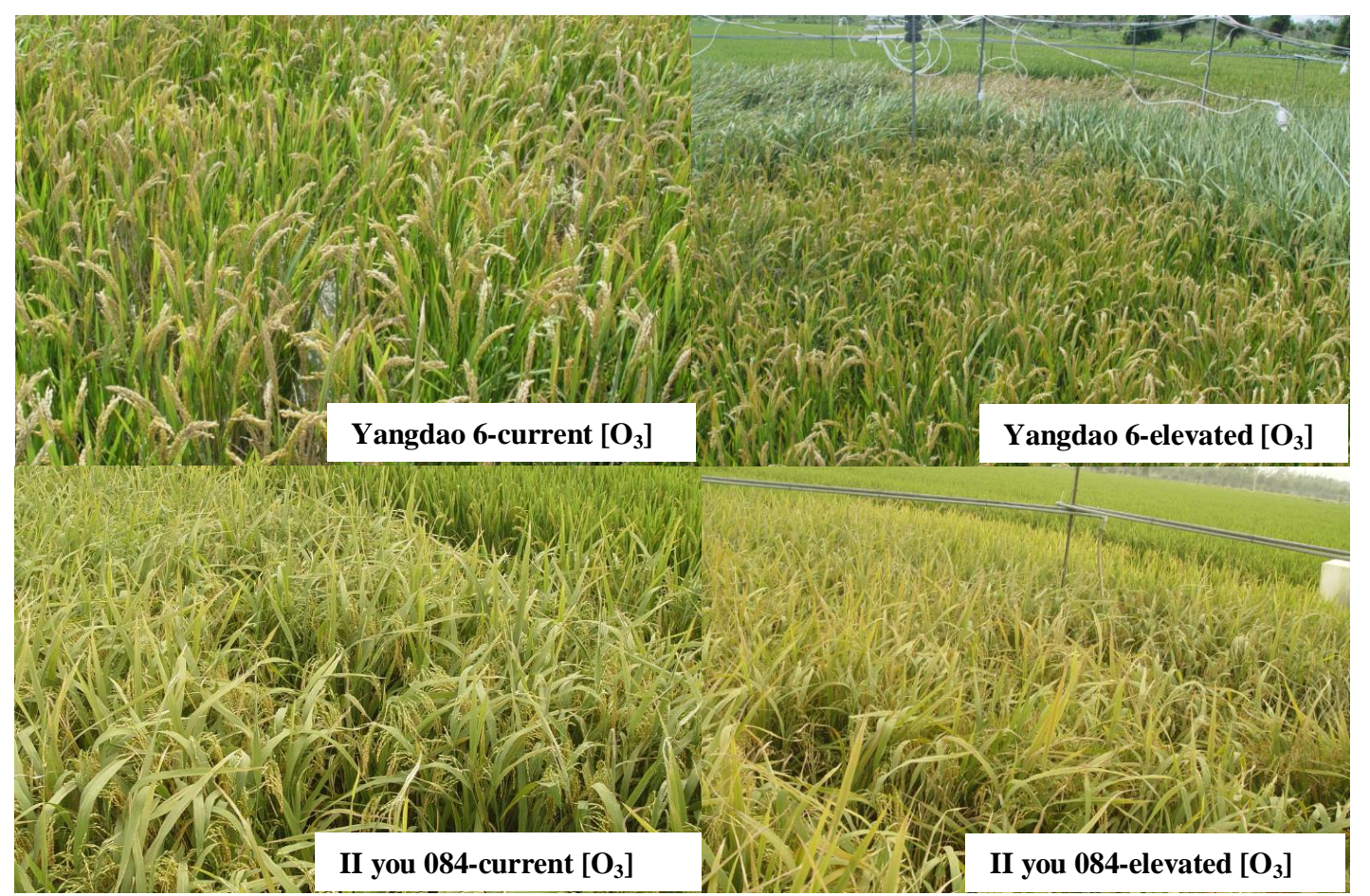

Figure 2. Ozone stress had no impact on growth stage of Yangdao 6, but obviously accelerated phonological development of II you-084 
Yangdao 6

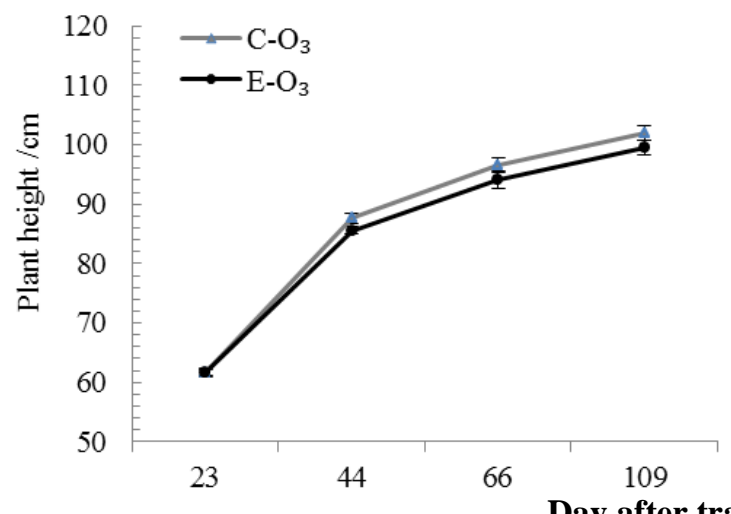

II you 084

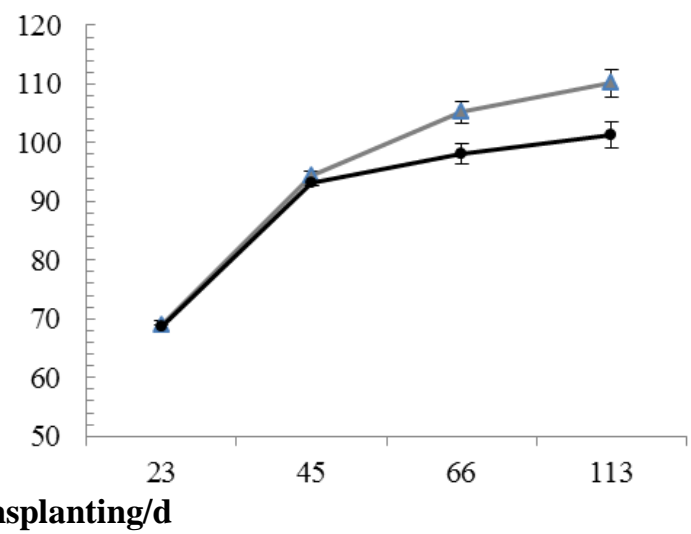

Figure 3. Effects of ozone concentration on plant height at different growth stage of Yangdao 6 and II you 084

Table 1. Effects of surface ozone concentration and plant density on growth stage of rice varieties

\begin{tabular}{|c|c|c|c|c|c|c|}
\hline \multirow[b]{2}{*}{ Cultivar } & \multirow{2}{*}{$\begin{array}{c}\mathrm{O}_{3} \\
\text { treatment }\end{array}$} & \multicolumn{2}{|c|}{ Growth stage/mouth/day } & \multicolumn{3}{|c|}{ Growth period/days } \\
\hline & & $\begin{array}{l}\text { Heading } \\
\text { stage }\end{array}$ & Maturity & $\begin{array}{l}\text { Transplanting } \\
\text { to heading }\end{array}$ & $\begin{array}{l}\text { Heading to } \\
\text { maturity }\end{array}$ & $\begin{array}{l}\text { Transplanting } \\
\text { to maturity }\end{array}$ \\
\hline \multirow{2}{*}{ Yangdao 6} & $\mathrm{C}-\mathrm{O}_{3}$ & $8 / 28$ & $10 / 16$ & 68 & 49 & 117 \\
\hline & $\mathrm{E}-\mathrm{O}_{3}$ & $8 / 28$ & $10 / 16$ & 68 & 49 & 117 \\
\hline \multirow{2}{*}{ II you 084} & $\mathrm{C}-\mathrm{O}_{3}$ & $8 / 29$ & $10 / 19$ & 69 & 51 & 120 \\
\hline & $\mathrm{E}-\mathrm{O}_{3}$ & $8 / 26$ & $10 / 12$ & 66 & 47 & 113 \\
\hline
\end{tabular}

\section{Dry matter production and biomass}

High concentration of $\mathrm{O}_{3}$ reduced the biomass of Yangdao 6 by $17.6 \%(p<0.01)$, among which $23.5 \%, 20.1 \%$ and $9.3 \%$ were decreased at low, medium and high density respectively, with all reaching a significant level. The elevated ozone concentration decreased the biomass of II you 084 by $25.4 \%$ ( $p<0.01$ ), among which $29.2 \%, 25.6 \%$ and $22.0 \%$ were significantly decreased respectively (Fig. 4). The effects of ozone multiplied by varieties and ozone multiplied by density on biomass of rice reached the significant level of 0.05 and 0.1 respectively.

The biomass of rice was closely related to the dry matter production in each growth stage. High concentration of $\mathrm{O}_{3}$ reduced the dry matter production of Yangdao 6 from tillering to jointing, jointing to heading, heading to maturity stage by $1.8 \%, 29.2 \%$ $(p<0.01)$ and $19.0 \%(p<0.05)$ respectively, and decreased II you 084 with the same stage by $8.6 \%(p<0.05), 13.6 \%(\mathrm{p}<0.1)$ and $46.5 \%(p<0.01)$ respectively (Table 2$)$. The analysis of variance showed that the interaction of ozone and varieties had a significant effect on the biomass from heading to maturity of rice. The high concentration of $\mathrm{O}_{3}$ had no significant effect on the harvest index of Yangdao 6 but decreased it of II you 084 by $9 \%(p<0.05)$ (Fig. 5). Variance analysis showed that the effect of ozone multiplied by varieties on harvest index of rice reached 0.1 significant level. 

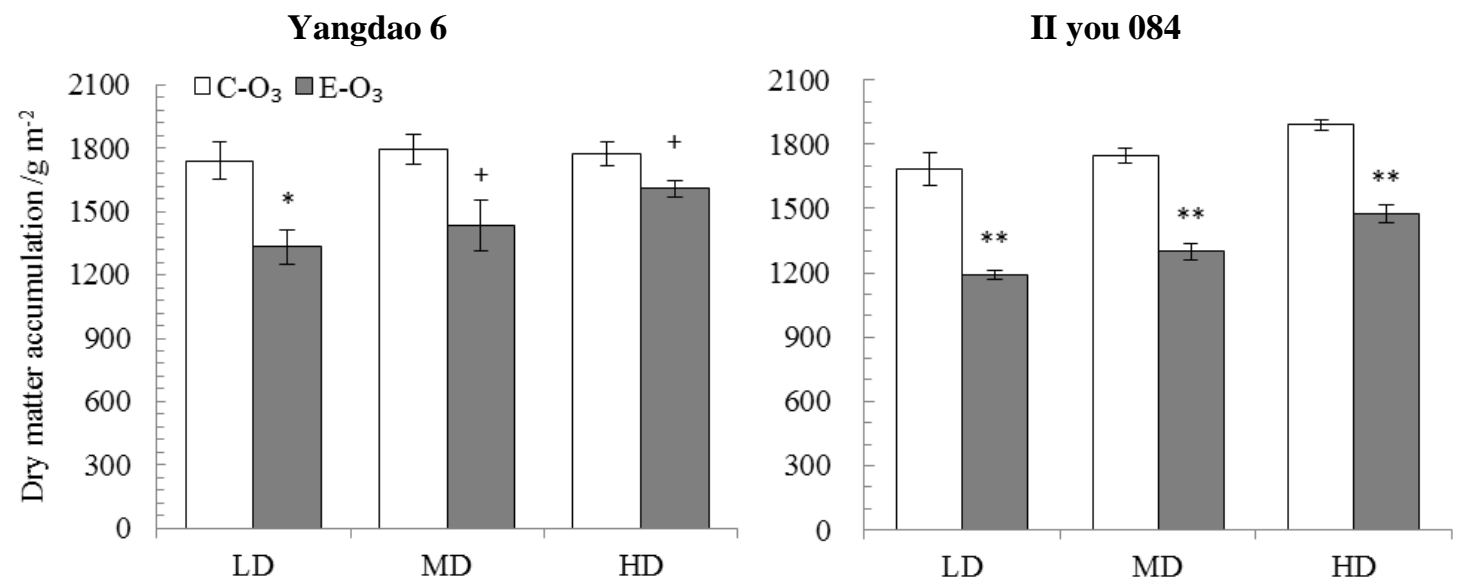

Figure 4. Effects of surface ozone concentration and plant density on biomass yield of Yangdao 6 and II you 084. ANOVA: Cultivar $(P<0.05)$; Density $(P<0.01)$; Ozone $(P<0.01) ; O_{3} \times$ Cultivar $(P<0.05) ; O_{3} \times$ Density $(P<0.1)$; Cultivar $\times$ Density $(p>0.1) ; O_{3} \times$ Cultivar $\times$ Density $(p>0.1)$

Table 2. Effects of surface ozone concentration and plant density on dry matter production of rice varieties

\begin{tabular}{|c|c|c|c|c|c|}
\hline \multirow{2}{*}{ Cultivar } & \multirow{2}{*}{ Density } & \multirow{2}{*}{$\mathrm{O}_{3}$ treatment } & \multicolumn{3}{|c|}{ Dry matter production $/ \mathrm{g} / \mathrm{m}^{2}$} \\
\hline & & & Tillering to jointing & Jointing to heading & Heading to maturity \\
\hline \multirow{6}{*}{ Yangdao 6} & \multirow{2}{*}{$\mathrm{LD}$} & $\mathrm{C}-\mathrm{O}_{3}$ & $336 \pm 21$ & $389 \pm 52$ & $892 \pm 75$ \\
\hline & & $\mathrm{E}-\mathrm{O}_{3}$ & $339 \pm 15$ & $245 \pm 41$ & $629 \pm 90$ \\
\hline & \multirow{2}{*}{ MD } & $\mathrm{C}-\mathrm{O}_{3}$ & $318 \pm 5$ & $541 \pm 29$ & $776 \pm 96$ \\
\hline & & $\mathrm{E}-\mathrm{O}_{3}$ & $313 \pm 17$ & $393 \pm 58$ & $573 \pm 92$ \\
\hline & \multirow[t]{2}{*}{$\mathrm{HD}$} & $\mathrm{C}-\mathrm{O}_{3}$ & $351 \pm 20$ & $449 \pm 26$ & $793 \pm 47$ \\
\hline & & $\mathrm{E}-\mathrm{O}_{3}$ & $321 \pm 34$ & $338 \pm 24$ & $792 \pm 28$ \\
\hline \multirow{6}{*}{ II you 084} & \multirow{2}{*}{$\mathrm{LD}$} & $\mathrm{C}-\mathrm{O}_{3}$ & $341 \pm 8$ & $528 \pm 55$ & $701 \pm 105$ \\
\hline & & $\mathrm{E}-\mathrm{O}_{3}$ & $293 \pm 13$ & $427 \pm 19$ & $371 \pm 35$ \\
\hline & \multirow{2}{*}{ MD } & $\mathrm{C}-\mathrm{O}_{3}$ & $365 \pm 32$ & $567 \pm 24$ & $662 \pm 58$ \\
\hline & & $\mathrm{E}-\mathrm{O}_{3}$ & $342 \pm 22$ & $441 \pm 48$ & $383 \pm 64$ \\
\hline & \multirow[t]{2}{*}{$\mathrm{HD}$} & $\mathrm{C}-\mathrm{O}_{3}$ & $416 \pm 28$ & $454 \pm 46$ & $852 \pm 59$ \\
\hline & & $\mathrm{E}-\mathrm{O}_{3}$ & $390 \pm 25$ & $470 \pm 50$ & $432 \pm 71$ \\
\hline \multirow{7}{*}{\multicolumn{2}{|c|}{ ANOVA ( $p$ value) }} & $\mathrm{O}_{3}$ & 0.068 & 0.001 & 0.000 \\
\hline & & Cultivar & 0.074 & 0.004 & 0.000 \\
\hline & & Density & 0.089 & 0.030 & 0.200 \\
\hline & & $\mathrm{O}_{3} \times \mathrm{D}$ & 0.859 & 0.423 & 0.553 \\
\hline & & $\mathrm{O}_{3} \times \mathrm{C}$ & 0.400 & 0.298 & 0.031 \\
\hline & & $\mathrm{C} \times \mathrm{D}$ & 0.365 & 0.641 & 0.598 \\
\hline & & $\mathrm{O}_{3} \times \mathrm{D} \times \mathrm{C}$ & 0.784 & 0.662 & 0.391 \\
\hline
\end{tabular}

The values in the table represent average values \pm standard errors 

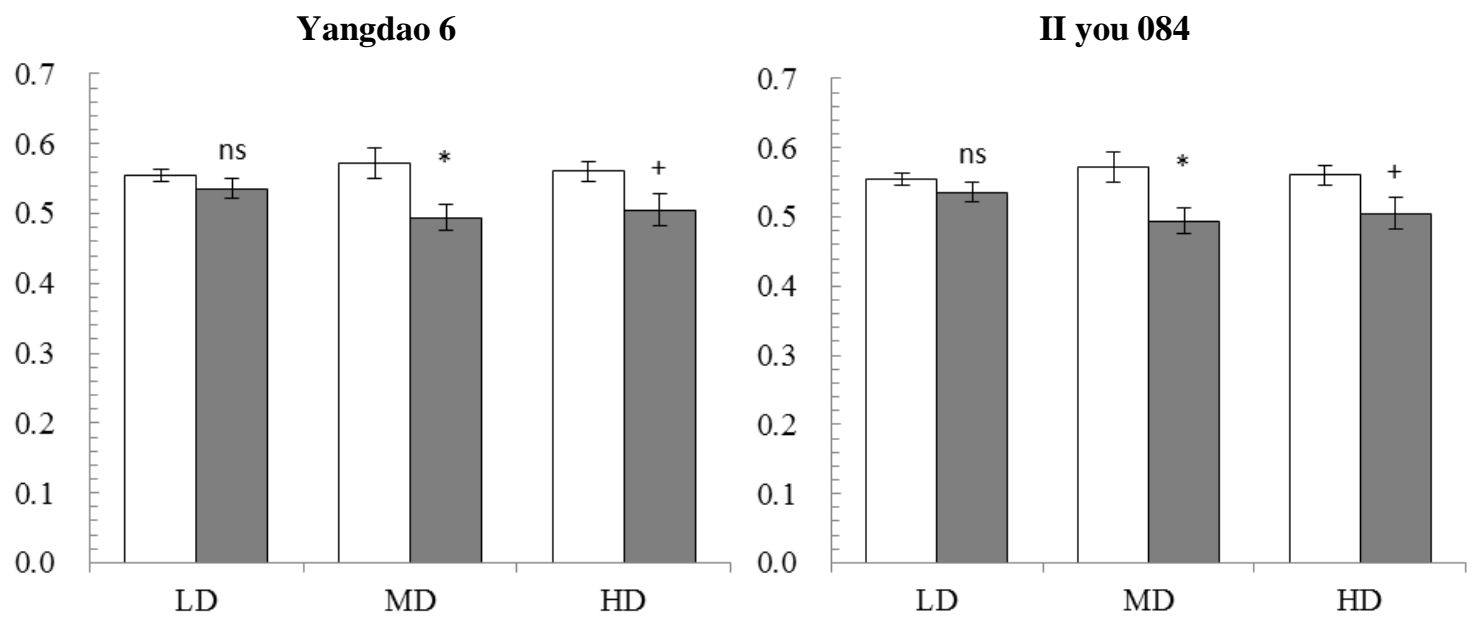

Figure 5. Effects of surface ozone concentration and plant density on harvest index of Yangdao 6 and II-you 084. ANOVA: Cultivar ( $p>0.1)$; Density ( $p>0.1)$; Ozone $(P<0.1) ; \mathrm{O}_{3} \times$ Cultivar ( $P$ < 0.1); $O_{3} \times$ Density $(p>0.1)$; Cultivar $\times$ Density $(p>0.1) ; O_{3} \times$ Cultivar $\times$ Density $(p>0.1)$

\section{Grain yield and yield components}

$\mathrm{O}_{3}$ treatment decreased the grain yield of Yangdao 6 by $142.0 \mathrm{~g} / \mathrm{m}^{2}$, which was $15.9 \%(p<0.01)$ reduction compared to the control, with the decrease of $23.5 \%$ $(p<0.01), 14 \%(p<0.1)$ and $9.9 \%(p<0.1)$ under low, medium and high density. The $\mathrm{O}_{3}$ stress reduced the yield of II you 084 by $278.5 \mathrm{~g} / \mathrm{m}^{2}$, which was $27.3 \%(p<0.01)$ reduction compared to the control, with the significant decrease of $26.9 \%, 25.0 \%$ and $30.0 \%$ respectively under low, medium and high density (Fig. 6). Variance analysis showed that the interaction of $\mathrm{O}_{3}$ and varieties had a significant effect on rice yield, and the interaction of three factors of $\mathrm{O}_{3}$, varieties and density had a weak interaction effect on the rice yield $(p=0.20)$, which show that the effect of $\mathrm{O}_{3}$ on the grain yield of Yangdao 6 decreased with the increase of density.
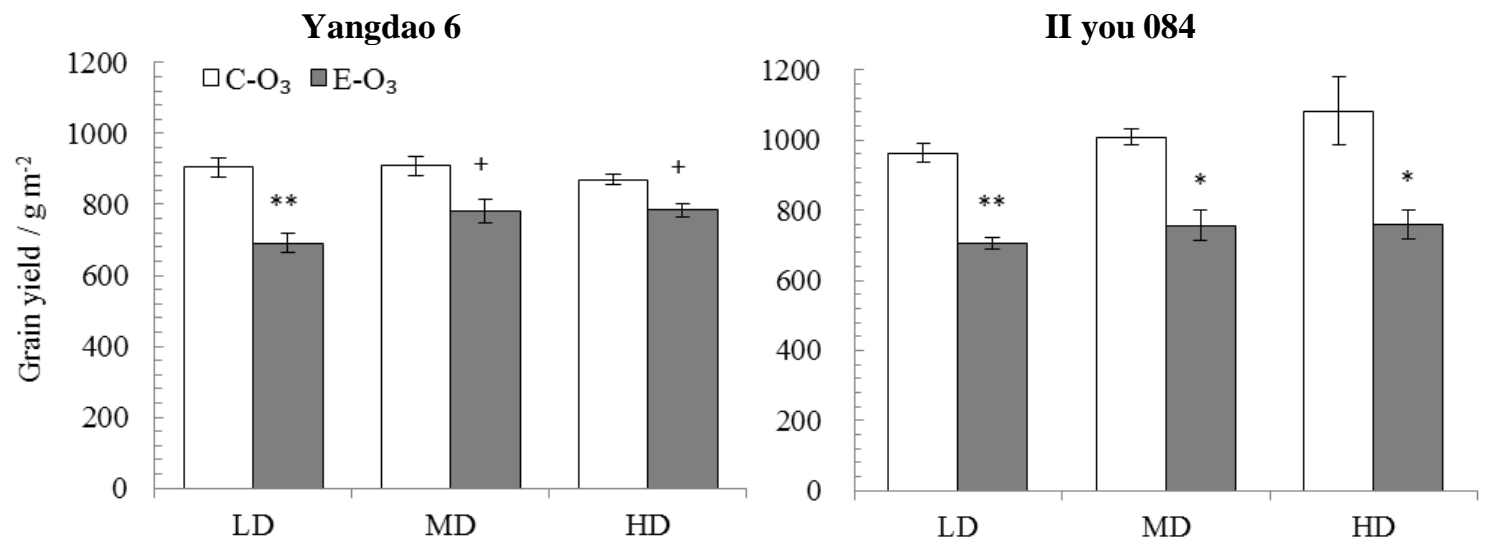

Figure 6. Effects of surface ozone concentration and plant density on grain yield of Yangdao 6 and II you 084. ANOVA: Cultivar ( $P<0.05)$; Density $(p>0.1)$; Ozone $(P<0.01) ; O_{3} \times$ Cultivar $(P<0.01) ; O_{3} \times$ Density $(p>0.1)$; Cultivar $\times$ Density $(p>0.1) ; O_{3} \times$ Cultivar $\times$ Density $(p>0.1)$ 
The high concentration of $\mathrm{O}_{3}$ had no significant effects on the spike number per unit area of Yangdao 6 and II you 084. But from the composition of the spike number, the elevated ozone concentration significantly decreased the maximum tiller number of rice by $8.5 \%$, increased productive tiller ratio of rice by $6.6 \%(p<0.05)($ Fig. 7$) . \mathrm{O}_{3}$ stress had no significant effect on the spikelet number per panicle of Yangdao 6 but decreased it of II you 084 by $22.0 \%$ ( $p<0.01$ ), with the significant decrease of $15.7 \%, 27.6 \%$ and $21.9 \%$ under low, medium and high density (Table 3). Analyzing from the composition of the spikelet number per panicle, the increase of $\mathrm{O}_{3}$ concentration decreased the dry weight per stem at heading stage of Yangdao 6 by $11.1 \%(p<0.05)$ but increased the ratio of spikelet number to stem dry weight of Yangdao 6 by $13.2 \mathrm{~g}(p<0.05)$. High concentration of $\mathrm{O}_{3}$ reduced the dry weight per stem at heading stage and the ratio of spikelet number to stem dry weight of II you 084 by $12.7 \%(p<0.05)$ and $10.7 \%$ $(p<0.05)$ respectively $($ Fig. 8$)$. Ozone stress reduced the spikelet number per unit area of Yangdao 6 by $4.8 \%(p>0.05)$, and decreased it of II you 084 by $21.7 \%(p<0.01)$ on average, among which $20.3 \%, 26.0 \%$ and $18.8 \%$ were significantly decreased respectively under low, medium and high density (Table 3). High concentration of $\mathrm{O}_{3}$ reduced the filled grain percentage of Yangdao 6 and II you 084 by $6.4 \%(p<0.05)$ and $11.9 \%(p<0.01)$ respectively. The filled grain weight of Yangdao 6 and II you 084 were decreased by $2.3 \%(p<0.05)$ and $4.7 \%(p<0.01)$ respectively to ozone stress (Table 3).
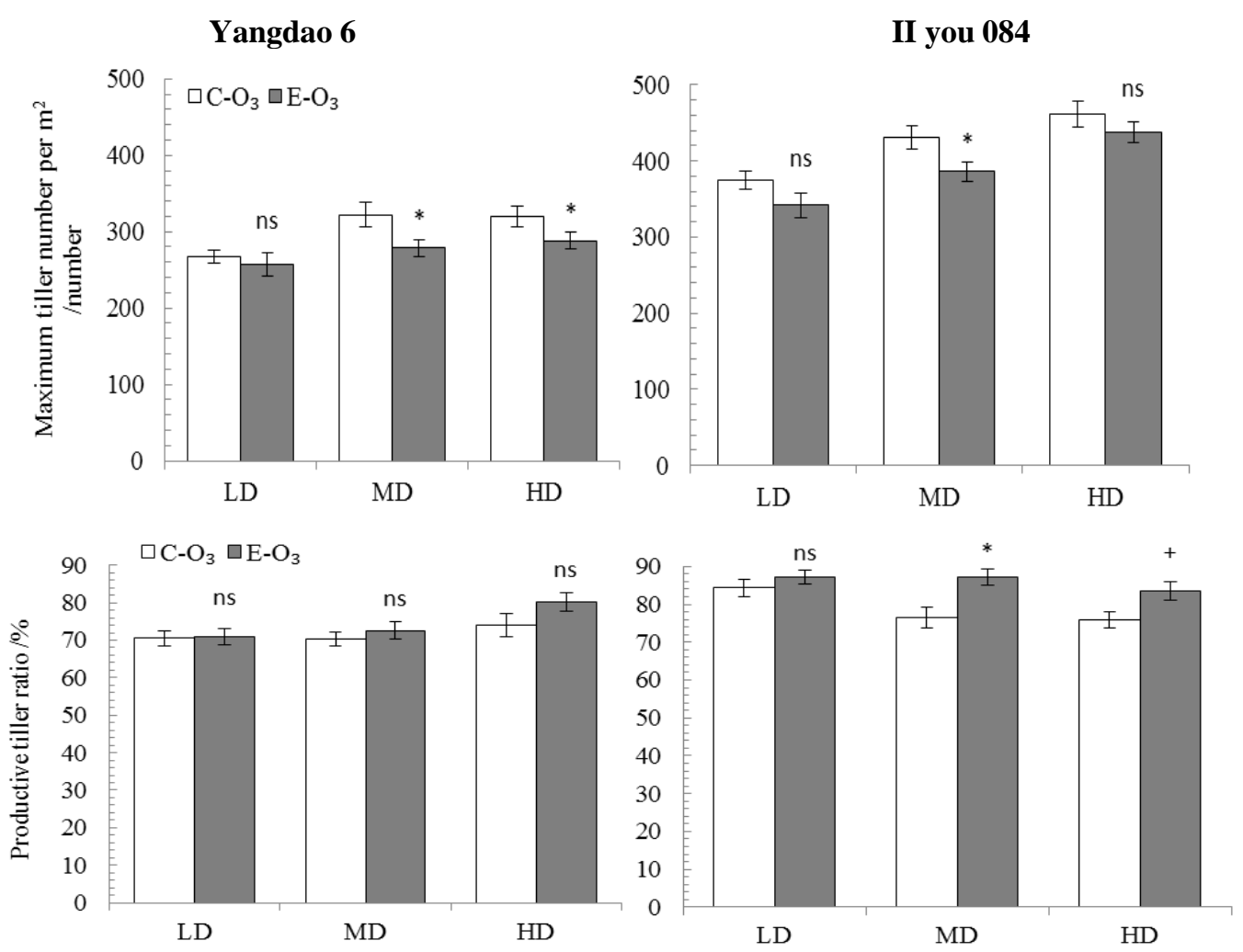

Figure 7. Effects of surface ozone concentration and plant density on maximum tiller number per square meter and productive tiller ratio of Yangdao 6 and II-you 084. ANOVA (M means maximum tiller number per square meter, $P$ means productive tiller ratio): $M$ : Cultivar $(P<$ $0.01)$; Density $(P<0.01)$; Ozone $(P<0.01) ; O_{3} \times C(p>0.1) ; O_{3} \times D(p>0.1) ; C \times D(p>$ $0.1) ; O_{3} \times C \times D(p>0.1)$. P: Cultivar $(P<0.01) ;$ Density $(p>0.1) ;$ Ozone $(P<0.05) ; O_{3} \times$ $C(p>0.1) ; O_{3} \times D(p>0.1) ; C \times D(p>0.1) ; O_{3} \times C \times D(p>0.1)$ 

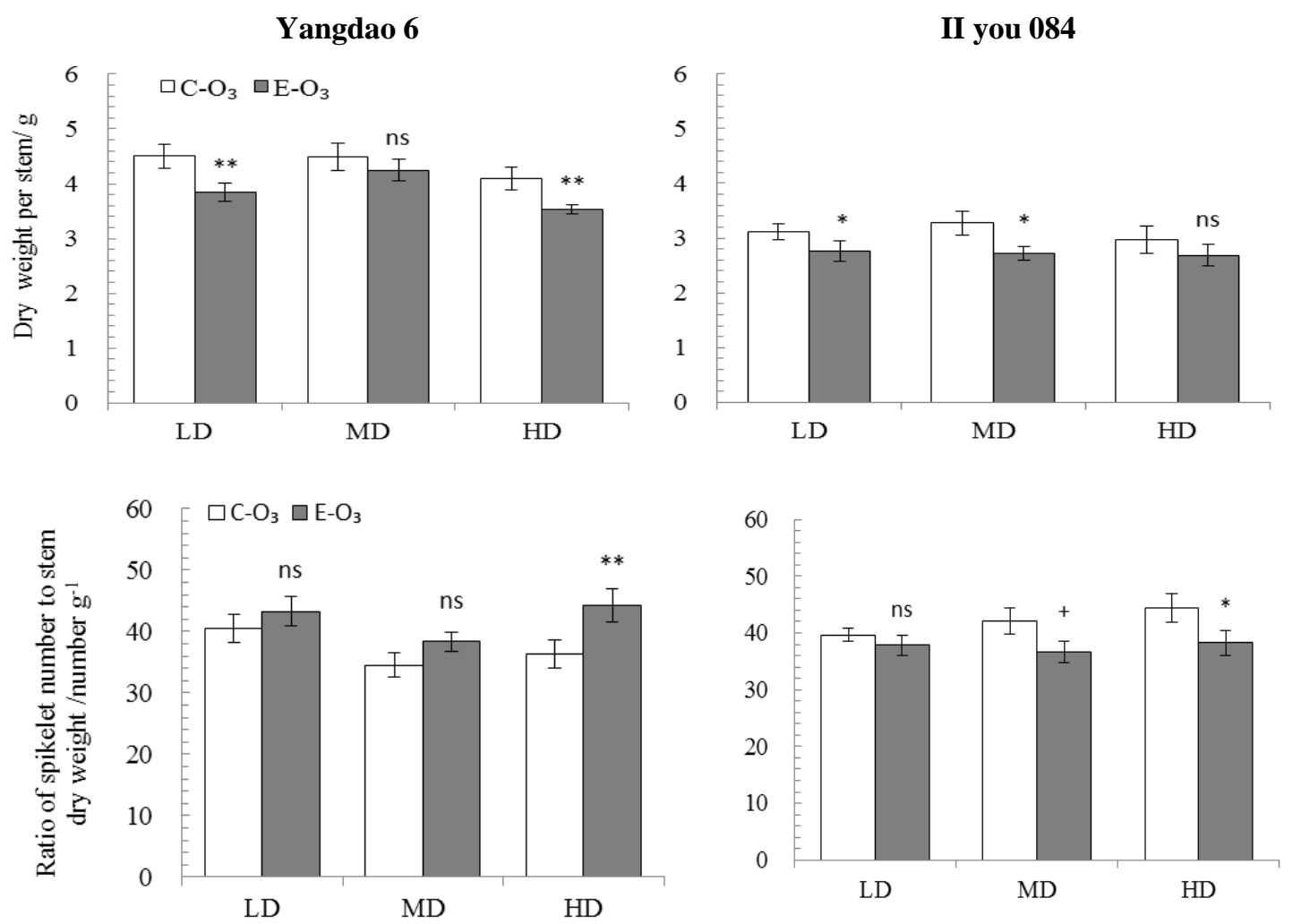

Figure 8. Effects of surface ozone concentration and plant density on dry weight per stem at heading stage and ratio of spikelet number to stem dry weight of Yangdao 6 and IIyou 084 under FACE condition. ANOVA ( $D$ means dry weight per stem at heading stage, $R$ means ratio of spikelet number to stem dry weight): D: Cultivar $(P<0.01)$; Density $(P<0.05)$; Ozone $(P<$ $0.01) ; O_{3} \times C(p>0.1) ; O_{3} \times D(p>0.1) ; C \times D(p>0.1) ; O_{3} \times C \times D(p>0.1) . R: C u l t i v a r$ $(p>0.1) ;$ Density $(p>0.1) ;$ Ozone $(p>0.1) ; O_{3} \times C(P<0.05) ; O_{3} \times D(p>0.1) ; C \times D(p>$

$$
0.1) ; O_{3} \times C \times D(p>0.1)
$$

\section{Discussion}

\section{Phenology and plant height}

Previous studies in gas chambers showed that the phenology of rice was unchanged or shortened under ozone stress (Yang et al., 2008). Our study found that $\mathrm{O}_{3}$ treatment, which is $25 \%$ higher than the ambient concentration, had no significant effects on phenology development of Yangdao 6, conventional rice. However, the heading date and maturity stage of super hybrid rice II you 084 were 3 days and 7 days earlier respectively under $\mathrm{O}_{3}$ treatment (Table 1; Fig. 2). The effect on the super hybrid rice was similar to that of hybrid rice "Shanyou 63" under FACE condition (Shi et al., 2009; Wang et al., 2012). It was inferred that the effect of high $\mathrm{O}_{3}$ concentration on phenology of hybrid rice or super hybrid rice in the future may be more significant than that of conventional rice. Many studies on plant height showed that the increase of ozone concentration generally reduced the plant height of rice, and the decline varied with varieties (Abhijit and Agrawal, 2012; Hiroko et al., 2012; Shi et al., 2009). This research showed that $\mathrm{O}_{3}$ treatment had no significant effect on the plant height of Yangdao 6 but decreased the plant height of II you 084 by7.8\%. From the dynamic response of high sensitive variety II you 084, the effect of ozone stress on the plant 
height gradually increased with the plant growth process (Fig. 3), showing a certain cumulative effect.

Table 3. Effects of surface ozone concentration and plant density on yield components of rice varieties

\begin{tabular}{|c|c|c|c|c|c|c|c|}
\hline Cultivar & Density & $\begin{array}{c}\mathrm{O}_{3} \\
\text { treatment }\end{array}$ & $\begin{array}{c}\text { Panicle } \\
\text { number per } \\
\mathbf{m}^{2}\end{array}$ & $\begin{array}{c}\text { Spikelet } \\
\text { number per } \\
\text { panicle }\end{array}$ & $\begin{array}{c}\text { Spikelets } \\
\text { per } \mathrm{m}^{2} / \times 10^{4}\end{array}$ & $\begin{array}{c}\text { Filled grain } \\
\text { percentage/\% }\end{array}$ & $\begin{array}{c}\text { Filled } \\
\text { grain } \\
\text { weight } / \mathbf{m g}\end{array}$ \\
\hline \multirow{6}{*}{ Yangdao 6} & \multirow{2}{*}{ LD } & $\mathrm{C}-\mathrm{O}_{3}$ & $188 \pm 7$ & $182 \pm 3$ & $3.4 \pm 0.1$ & $84 \pm 2$ & $34.5 \pm 0.1$ \\
\hline & & $\mathrm{E}-\mathrm{O}_{3}$ & $183 \pm 11$ & $167 \pm 3$ & $3.0 \pm 0.2$ & $74 \pm 2$ & $33.3 \pm 0.5$ \\
\hline & \multirow{2}{*}{ MD } & $\mathrm{C}-\mathrm{O}_{3}$ & $227 \pm 8$ & $155 \pm 6$ & $3.5 \pm 0.1$ & $80 \pm 2$ & $34.5 \pm 0.1$ \\
\hline & & $\mathrm{E}-\mathrm{O}_{3}$ & $203 \pm 5$ & $163 \pm 6$ & $3.3 \pm 0.1$ & $80 \pm 2$ & $33.7 \pm 0.3$ \\
\hline & \multirow{2}{*}{$\mathrm{HD}$} & $\mathrm{C}-\mathrm{O}_{3}$ & $236 \pm 6$ & $149 \pm 4$ & $3.5 \pm 0.1$ & $81 \pm 1$ & $34.6 \pm 0.1$ \\
\hline & & $\mathrm{E}-\mathrm{O}_{3}$ & $231 \pm 15$ & $157 \pm 3$ & $3.6 \pm 0.2$ & $74 \pm 2$ & $34.3 \pm 0.4$ \\
\hline \multirow{6}{*}{ II you 084} & \multirow{2}{*}{ LD } & $\mathrm{C}-\mathrm{O}_{3}$ & $315 \pm 4$ & $124 \pm 3$ & $3.9 \pm 0.1$ & $91 \pm 1$ & $28.3 \pm 0.4$ \\
\hline & & $\mathrm{E}-\mathrm{O}_{3}$ & $298 \pm 5$ & $104 \pm 2$ & $3.1 \pm 0.1$ & $81 \pm 3$ & $26.9 \pm 0.1$ \\
\hline & \multirow{2}{*}{ MD } & $\mathrm{C}-\mathrm{O}_{3}$ & $330 \pm 5$ & $138 \pm 3$ & $4.5 \pm 0.1$ & $93 \pm 1$ & $28.0 \pm 0.3$ \\
\hline & & $\mathrm{E}-\mathrm{O}_{3}$ & $336 \pm 13$ & $100 \pm 4$ & $3.4 \pm 0.2$ & $82 \pm 4$ & $27.0 \pm 0.3$ \\
\hline & \multirow{2}{*}{$\mathrm{HD}$} & $\mathrm{C}-\mathrm{O}_{3}$ & $350 \pm 7$ & $132 \pm 9$ & $4.6 \pm 0.4$ & $90 \pm 1$ & $27.5 \pm 0.2$ \\
\hline & & $\mathrm{E}-\mathrm{O}_{3}$ & $366 \pm 7$ & $103 \pm 5$ & $3.8 \pm 0.1$ & $78 \pm 5$ & $26.1 \pm 0.4$ \\
\hline \multirow{6}{*}{\multicolumn{2}{|c|}{ ANOVA ( $p$ value) }} & $\mathrm{O}_{3}$ & 0.385 & 0.000 & 0.000 & 0.000 & 0.000 \\
\hline & & Cultivar & 0.000 & 0.000 & 0.000 & 0.001 & 0.000 \\
\hline & & Density & 0.000 & 0.028 & 0.005 & 0.387 & 0.784 \\
\hline & & $\mathrm{O}_{3} \times \mathrm{D}$ & 0.401 & 0.438 & 0.477 & 0.513 & 0.664 \\
\hline & & $\mathrm{O}_{3} \times \mathrm{C}$ & 0.244 & 0.000 & 0.005 & 0.112 & 0.271 \\
\hline & & $\mathrm{O}_{3} \times \mathrm{D} \times \mathrm{C}$ & 0.282 & 0.024 & 0.567 & 0.437 & 0.599 \\
\hline
\end{tabular}

The values in the table represent average values \pm standard errors

\section{Dry matter production and biomass}

Previous studies showed that high concentration of ozone significantly inhibited the dry matter production of rice, but the degree of influence varied greatly with different treatment concentration, variety and environment (Kobayashi et al., 1995; Jin et al., 2001; Pang et al., 2009; Hiroko et al., 2012). This result showed that the increase of ozone concentration decreased the biomass of rice by 22\%, in which Yangdao 6 and II you 084 were decreased by $17 \%$ and $25 \%$ respectively (Fig. 4). It showed that the loss of biomass of super hybrid rice may be higher than that of conventional rice under high ozone concentration in the future. According to different densities, the response of biomass of the two varieties to $\mathrm{O}_{3}$ stress decreased with the increase of density, especially Yangdao 6. Our study also showed that high concentration of ozone had little effect on the dry matter production of rice in the early stage of growth, but significantly decreased it in the middle and late stages of rice (Table 2). This indicated that the decline of the final productivity of rice under ozone stress was mainly related to the inhibition of growth in the middle and later growth period, especially in the later stage. 
Under ozone stress, the decrease of dry matter production from heading to maturity stage of II you $084(-47 \%)$ was significantly larger than that of Yangdao $6(-19 \%)$ (Table 2), which obviously resulted in the decrease of the final biomass of II you 084 was greater than that of Yangdao 6. According to the difference of different densities, there was significant interaction between ozone and density on the dry matter production during the reproductive growth stage (jointing to maturity) of Yangdao 6 . The response of dry matter production of Yangdao 6 to ozone stress decreased with the increase of density. The meta-analysis of Ainsworth (2008) on the gas chamber showed that the ozone concentration of $61 \mathrm{nl} / \mathrm{L}$ decreased the harvest index of rice by $5 \%$, compared with the filtered air $(n=19)$. Our results showed that high $\mathrm{O}_{3}$ concentration had no significant effect on the harvest index of Yangdao 6, significantly reduced it of II you 084 by $9 \%$ (Fig. 5), and the difference of response between two varieties reached a significant level.

\section{Yield components}

Previous studies on yield components of rice show that $\mathrm{O}_{3}$ stress had no significant effect on panicle number per unit area (Ainsworth, 2008). There were also studies showing that the panicle number per unit area of rice decreased under ozone stress, which was due to the decrease of tiller capability (Walid et al., 1995) or the decrease of productive tiller percentage (Maggs and Ashmore, 1998). This study showed that high concentration ozone had no significant effect on panicle number per unit area of conventional indica rice Yangdao 6 and super hybrid rice II you 084. Analyzing the constituent factors of panicle number per unit area, the increase of $\mathrm{O}_{3}$ concentration resulted in an average decrease of the maximum tiller number $9 \%$ and $7 \%$ increase in productive tiller percentage (Fig. 7). It indicated that the tiller capability was decreased, and the productive tiller percentage was increased under the ozone stress, which may be the main reason for the no significant change of panicle number per unit area. The majority of previous studies showed that the spikelet number per panicle of rice was decreased with ozone stress, and the decline was due to different ozone treatment (Kats et al., 1985; Jin et al., 2001; Feng et al., 2003; Bhatia et al., 2011) or different varieties (Shi et al., 2009; Wang et al., 2012; Hiroko et al., 2012). This study showed that high concentration ozone had no significant effect on the spikelet number per panicle of Yangdao 6, but significantly reduced it of II you 084 by $22 \%$ (Table 3). Ozone stress both decreased the dry weight per stem at heading stage and the ratio of spikelet number to stem dry weight of Yangdao 6, which resulted in a significant decrease in the spikelet number per panicle of Yangdao 6. Ozone stress significantly reduced the dry weight per stem at heading stage of II you 084, meanwhile, increased the ratio of spikelet number to stem dry weight. As a result, the spikelet number per panicle of II you 084 was not significantly changed. According to the differences among different densities, ozone multiplied by varieties and density also had significant interaction effects on the spikelet number per panicle of rice $(p=0.02)$. It showed that the effect of $\mathrm{O}_{3}$ on the spikelet number per panicle of II you 084 had no significant differences between different densities. For Yangdao 6, the high concentration of $\mathrm{O}_{3}$ decreased the spikelet number per panicle by $9 \%$ at low density, but increased slightly $(+5 \%, p>0.05)$.

The spikelet number per unit area of rice represents the yield capacity. The metaanalysis of Ainsworth (2008) on the gas chamber showed that the ozone concentration of $62 \mathrm{nl} / \mathrm{L}$ decreased the spikelet number per unit area of rice by 20\%, compared with the filtered air $(n=15)$. This study showed that high concentration of $\mathrm{O}_{3}$ significantly 
reduced the spikelet number per unit area of rice by 14\%, among which 5\% and $9.3 \%$ were decreased of Yangdao 6 and II you 084 respectively with significant differences among varieties. Combined with the change of the spikelet number per panicle, the effect of ozone stress on the spikelet number per unit area was mainly due to the influence of the spikelet number per panicle.

The filled grain percentage and filled grain weight reflected the grain filling ability of rice. Previous studies showed that high concentration of ozone reduced the filled grain percentage of rice. This study also showed that ozone stress decreased the filled grain percentage of Yangdao 6 and II you 084 by $6 \%$ and 12\% respectively, and the effect on the II you 084 was significantly greater than that of Yang Rice No. 6. The meta-analysis of Ainsworth (2008) on the gas chamber showed that the ozone concentration of $83 \mathrm{nl} / \mathrm{L}$ decreased filled grain weight of rice by $5 \%$, compared with the filtered air $(n=22)$. The meta-analysis of Feng (2009) showed that current ozone concentration (31-50 nl/L) decreased filled grain weight of rice by $3.1 \%$, compared with the filtered air. Recent FACE experiments in China showed that the filled grain weight of rice decreased with the increase of ozone stress, and the decline was due to different varieties or years (Shi et al., 2009; Wang et al., 2012). The results of this study showed that $\mathrm{O}_{3}$ stress reduced the filled grain weight of Yangdao 6 and II you 084 respectively $2 \%$ and 5\%, and the effect of $\mathrm{O}_{3}$ stress on the filled grain weight of Yangdao 6 decreased with the increasing density.

\section{Grain yields}

Previous studies had mostly shown that the increase of atmospheric ozone concentration significantly decreased the rice yield, and the decline was related to the control equipment of the experiment (Maggs et al., 1995), materials (Kobayashi et al., 1995; Maggs and Ashmore, 1998; Zheng et al., 1998; Jin et al., 2000), the concentration of $\mathrm{O}_{3}$ treatment (Asakawa et al., 1981; Heagle et al., 1991; Bai et al., 2002) and the treatment period (Morikawa et al., 1980; Asakawa et al., 1981; Chen et al., 2007). The meta-analysis of Ainsworth (2008) on the gas chamber showed that the ozone concentration of $61 \mathrm{nl} / \mathrm{L}$ significantly decreased yield of rice by $14 \%$, compared with the filtered air. Our results showed that the grain yield of rice was decreased $235 \mathrm{~g} / \mathrm{m}^{2}$ at high $\mathrm{O}_{3}$ concentration, with the significant decrease of 25\%, in which Yangdao 6 and II you 084 were decreased $16 \%$ and $27 \%$ respectively (Fig. 6), and the interaction between ozone and varieties reached a significant level. Combined with previous research results (Shi et al., 2009; Pang et al., 2009; Wang et al., 2012), it was inferred that compared with conventional rice, although hybrid rice and super hybrid rice have some yield advantages at present, the yield loss of them may be more significant in the future under the condition of high $\mathrm{O}_{3}$ concentration. From the perspective of yield components, the effect of ozone stress on yield of Yangdao 6 was mainly related to the decrease of filled grain percentage, followed by the decrease of the filled grain weight. That was, ozone stress mainly affects the fertilization process and filling process of Yangdao 6 . The main reason for the effect of ozone stress on the yield of II you 084 was the decrease of the spikelet number per area and filled grain percentage, then the filled grain weight. Ozone stress not only affected the spikelet formation of II you 084, but also affected the fertilization process and grain filling process, and the effect of the latter was significantly greater than that of Yangdao 6, so the loss of yield was more obvious. In terms of dry matter production and distribution, high concentration of ozone reduced the photosynthetic production of Yangdao 6 but had no significant effects on the proportion 
of photosynthesis to grain. Analyzing the effect on II you 084, on the one hand, ozone stress significantly decreased the biomass (the decrease was significantly higher than that of Yangdao 6), but also significantly reduced the distribution of dry matter in the grain, thus making the decline of grain yield of II you 084 more significant.

The results showed that there was a weak interaction effect among ozone, varieties and density on yield. There were no significant differences in the effect of $\mathrm{O}_{3}$ stress on the yield of II you 084 among different densities. However, the yield-loss of Yangdao 6 to high ozone concentration decreased significantly with the increase of density (at low, medium and high density, the yield was decreased $24 \%, 14 \%$ and $10 \%$ respectively). According to the factors of yield composition, the effect of ozone on the spikelet number per panicle, yield capacity and filled grain weight of Yangdao 6 decreased with the increase of density. However, the effects of ozone stress on the yield components of II you 084 had no significant differences among different densities. Analyzing from dry matter production, effects of ozone on dry matter production at reproductive stage of Yangdao 6 decreased with the increase of density, and the effects on biomass and yield showed the same trend among different densities. Effects of ozone stress on II you 084 had no significant difference among different densities.

\section{Conclusion}

The results showed that the loss of rice yield under the condition of high $\mathrm{O}_{3}$ concentration was caused by the decline of grain filling ability (conventional rice) or both the decrease of yield storage capacities and grain filling ability (super hybrid rice). The ozone stress effect of hybrid rice varieties was significantly higher than that of conventional rice varieties. Secondly, proper increase of planting density can alleviate the ozone stress effect of conventional rice varieties to some extent. Therefore, under the background of high ozone concentration in the future, we can first select highyielding conventional rice varieties with strong ozone resistance by properly increasing planting density, thus slowing down the production loss to a certain extent. Limited to the conditions, only two varieties and three densities were studied in our research. Further researches on the interaction of ozone with more varieties and more cultivation measures should be further expanded in the future.

Acknowledgements. This work was funded jointly by the Natural Science Foundation of Jiangsu Province (Grants Nos BK20151298) and Jiangsu overseas scholar program for university prominent young and middle-aged teachers and presidents. The FACE system instruments were supplied by the National Institute of Agro-Environmental Sciences and the Agricultural Research Center of Tohoku Region (Japan). We are grateful to Dr G Liu and HY Tang for their technical support in the free-air ozone release system.

\section{REFERENCES}

[1] Abhijit, S., Agrawal, S. B. (2012): Evaluating the response of two high yielding Indian rice cultivars against ambient and elevated levels of ozone by using open top chambers. - Journal of Environmental Management 95: 19-S24.

[2] Ainsworth, E. A. (2008): Rice production in a changing climate: a metal analysis of responses to elevated carbon dioxide and elevated ozone concentration. - Global Change Biology 14: 1-9. 
[3] Asakawa, F., Tanaka, H., Kusaka, S. (1981): Effects of air filtration on rice growth and yield. - Japanese Journal of Soil Science and Plant Nutrition 52: 201-206.

[4] Bai, Y. M., Guo, J. P., Wang, C. Y., Wen, M. (2002): The reaction and sensitivity experiment of $\mathrm{O}_{3}$ on rice and winter wheat. - Chinese Journal of Eco-Agriculture 10(1): 13-16.

[5] Bhatia, A., Ghosh, A., Kumar, V., Tomer, R., Singh S, D., Pathak, H. (2011): Effect of elevated tropospheric ozone on methane and nitrous oxide emission from rice soil in north India. - Agriculture, Ecosystems and Environment 144: 21-28.

[6] Chen, J., Zeng, Q., Zhu, J. G., Liu, G., Xie, Z. B., Tang, H. Y. (2011a): Interactive effects of elevated ozone and nitrogen on dry matter production, concentration and accumulation of nitrogen, phosphorus and potassium in winter wheat. - Ecology and Environmental Sciences 20(4): 616-622.

[7] Chen, J., Zeng, Q., Zhu, J. G., Liu, G., Cao, J. L., Xie, Z. B., Tang, H. Y., Kazuhiko, K. (2011b): Nitrogen supply mitigates the effects of elevated $\left[\mathrm{O}_{3}\right]$ on photosynthesis and yield in wheat. - Chin J Plant Ecol 35(5): 523-530.

[8] Chen, Z., Wang, X. K., Xie, J. Q., Zheng, Q. W., Feng, Z. Z., Ouyang, Z. Y., Feng, Z. W. (2007): Effects of ozone on production of rice (Oryza sativa L.) during grain filling stage. - Asian Journal of Ecotoxicology 2(2): 208-213.

[9] Feng, Z., Jin, M., Zhang, F. Z. (2003): Effects of ground-level ozone $\left(\mathrm{O}_{3}\right)$ pollution on the yields of rice and winter wheat in the Yangtze River Delta. - Journal of Environmental Sciences 15(3): 360-362.

[10] Feng, A. E., Kobayashi, K. (2009): Assessing the impacts of current and future concentrations of surface ozone on crop yield with meta-analysis. - Atmospheric Environ 43: 1510-1519.

[11] Fiscus, E. L., Booker, F. L., Burkey, K. O. (2005): Crop responses to ozone: uptake, modes of action, carbon assimilation and partitioning. - Plant, Cell and Environment 28: 997-1011.

[12] Fowler, D., Cape, J. N., Coyle, M. (1999): Modelling photochemical oxidant formation, transport, deposition and exposure of terrestrial ecosystems. - Environ Pollut 100: 4355.

[13] Fuhrer, J., Skarby, L., Ashmore, M. R. (1997): Critical levels for ozone effect on vegetation in Europe. - Environmental Pollution 97: 91-106.

[14] Heagle, A. S., Miller, J. E., Rawtings, J. O. (1991): Effect of growth stage on soybean response to chronic ozone exposure. - Journal of Environmental Quality 20: 562-570.

[15] Hiroko, S., Setsuko, K., Yo, H. N., Nisar, A. K., Yoshihisa, K. (2012): Proteomic analysis of rice response involved in reduction of grain yield under elevated ozone stress. - Environmental and Experimental Botany 77: 108-116.

[16] IPCC (2007): Climate Change 2007: The Physical Science Basis. - In: Solomon, S., Qin, D., Manning, M., Chen, Z., Marquis, M., Averyt, K. B., Tignor, M., Miller, H. (eds.) Contribution of Working Group I to the Fourth Annual Assessment Report of the Intergovernmental Panel on Climate Change. Cambridge University Press, Cambridge, pp. 996-996.

[17] Jin, M. H., Feng, Z. W., Zhang, F. Z. (2000): Effects of Ozone on membrane lipid peroxidation and antioxidant system of rice leaves. - Environmental Science 21(3): 1-5.

[18] Jin, M. H., Feng, Z. Z., Zhang, F. Z. (2001): Impact of ozone on the biomass and yield of rice in open-top chambers. - Journal of Environmental Sciences 13(2): 233-236.

[19] Kats, G., Dawson, P. J., Bytnerowicz, A. (1985): Effects of ozone or sulfur dioxide on growth and yield of rice. - Agriculture, Ecosystems and Environment 14: 103-117.

[20] Kobayashi, K., Okada, M., Nouchi, I. (1995): Effects of ozone on dry matter partition and yield of Japanese cultivar of rice (Oryza saliva L.). - Agriculture, Ecosystems and Environment 53: 109-122. 
[21] Li, C. H., Zhu, J. G., Zeng, Q., Luo, K. J., Liu, B., Liu, G., Tang, H. Y. (2017): Different responses of transgenic $\mathrm{Bt}$ rice and conventional rice to elevated ozone concentration. - Environ Sci Pollut Res 24: 8352-8362.

[22] Lie, G. W., Ye, L. H., Xue, L. (2014): Effects of ozone stress on major plant physiological functions. - Acta Ecologica Sinica 34(2): 294-306.

[23] Logan, J. A. (1985): Tropospheric ozone-seasonal behaviour, trends and anthropogenic influence. - J Geophys Res 90: 10463-10482.

[24] Long, S. P., Ainsworth, E. A. (2005): Global food insecurity: treatment of major food crop s with elevated carbon dioxide or ozone under large scale fully open-air conditions suggests recent models may have overestimated future yields. - Philosophical Transactions of the Royal Society B: Biological Sciences 360: 00 2011-2020.

[25] Luo, K. J., Zhu, J. G., Liu, G., Tang, H. Y., Li, C. H., Zeng, Q. (2012): Effects of elevated ozone on leaf photosynthesis of rice (Oryza sativa L.) and mitigation with high nitrogen supply. - Ecology and Environmental Sciences 21(3): 481-488.

[26] Luo, K. J., Zhu, J. G., Liu, G., Tang, H. Y., Li, C. H., Zeng, Q. (2013): Responses of Dry Matter Production and Distribution in Rice (Oryza sativa L.) to Ozone and High Nitrogen Supply. - Chin J Appl Environ Biol 19(2): 286-292.

[27] Maggs, R., Ashmore, M. R. (1998): Growth and yield responses of Pakistan rice (Oryza sativa L.) cultivars to $\mathrm{O}_{3}$ and $\mathrm{NO}_{2}$. - Environmental Pollution 103: 159-170.

[28] Maggs, R., Wahid, A., Shamsi, S. R. A. (1995): Effects of ambient air pollution cereal yield in Pakistan. - Water, Air, And Soil Pollution 85: 1311-1316.

[29] Meehl, G. A., Stocker, T. F., Collins, W. D. (2007): Global Climate Projections. Cambridge University Press, Cambridge.

[30] Morgan, P. B., Mies, T. A., Bollero, G. A. (2006): Season-long elevation of ozone concentration to projected 2050 levels under fully open-air conditions substantially decreases the growth and production of soybean. - New Phytologist 170(2): 333-343.

[31] Morikawa, M., Matsumaru, T., Matsuoka, Y. (1980): The effect of ozone on the growth of rice plants. - Bulletin of the Chiba Prefectural Agricultural Experiment Station. 21: 11-18.

[32] Pang, J., Kazuhiko, K., Zhu, J. G. (2009): Yield and photosynthetic characteristics of flag leaves in Chinese rice (Oryza sativa L.) varieties subjected to free-air release of ozone. - Agriculture, Ecosystems and Environment 132: 203-211.

[33] Peng, B., Li, P. L., Lai, S. K., Yang, L. X., Wang, Y. L. (2016): Effects of ozone stress on yield formation and dry matter accumulation of rice under different source-sink processes. - Oxidation Communications 39: 2326-2336.

[34] Shi, G. Y., Yang, L. X., Wang, Y. X., Kobayashi, K., Zhu, J. G. (2009): Impact of elevated ozone concentration on yield of four Chinese rice cultivars under fully openair field conditions. - Agriculture, Ecosystems and Environment 131: 178-184.

[35] Sitch, S., Cox, P. M., Collins, W. J. (2007): Indirect radiative forcing of climate change through ozone effects on the land-carbon sink. - Nature 448: 791-795.

[36] Tang, H. Y., Liu, G., Han, Y. (2011): A system for free-air ozone concentration elevation with rice and wheat: control performance and ozone exposure regime. Atmospheric Environment 45(35): 6276-6282.

[37] Volz, A., Kley, D. (1988): Evaluation of the montsouris series of ozone measurements made in the 19th-century. - Nature 332: 240-242.

[38] Wahid, A., Maggs, R., Shamsi, S. R. A. (1995): Effects of air pollution on rice yield in the Pakistan Punjab. - Environmental Pollution 90: 323-329.

[39] Wang, Y. X., Yang, L. X., Kobayashi, K., Zhu, J. G., Chen, C. P., Yang, K. F., Tang, H. Y., Wang, Y. L. (2012): Investigations on spikelet formation in hybrid rice as affected by elevated tropospheric ozone concentration in China. - Agriculture, Ecosystems and Environment 150: 63-71.

[40] WMO (1991): Scientific assessment of ozone depletion: Chapter 21. Preprint December. 17. - WMO, Geneva. 
[41] Yang, L. X., Wang, Y. L., Shi, G. Y., Wang, Y. X., Zhu, J. G., Kazuhiko, K., Lai, S. K. (2008): Responses of rice growth and development to elevated near-surface layer ozone $\left(\mathrm{O}_{3}\right)$ concentration. - Chin J Appl Ecol 19(4): 901-910.

[42] Zheng, Y., Stevenson, K. J., Barrowcliffe, R. (1998): Ozone levels in Chongqing: A potential threat to crop plants commonly grown in the region. - Environmental Pollution 99: 299-308. 